\title{
The Efficacy of the Narrative Therapy Approach in Reducing Couples' Conflicts Through Couples Therapy
}

\author{
Parvin Hamidi, ${ }^{1}$ Seyfollah Bahari, ${ }^{1}$ Seyed Ali Mostafavi, ${ }^{2}$ and Morteza Shamohammadi ${ }^{3,}$ \\ ${ }^{1}$ Roudehen Branch, Islamic Azad University, Tehran, IR Iran \\ ${ }^{2}$ Psychiatry Research Center, Roozbeh Hospital, Tehran University of Medical Sciences, Tehran, IR Iran \\ ${ }^{3}$ Psychiatry and Clinical Psychology Research Center, Tehran University of Medical Sciences, Tehran, IR Iran \\ "Corresponding author: Morteza Shamohammadi, Psychiatry and Clinical Psychology Research Center, Tehran University of Medical Sciences, Tehran, IR Iran. E-mail: \\ morteza.shah@chmail.ir
}

Received 2016 February 09; Revised 2016 July 25; Accepted 2016 August 10.

\begin{abstract}
Background: Conflict among couples is one of the most important issues in the family and often causes wives to refer for therapy. One of the most important therapeutic approaches is narrative therapy, the efficacy of which is investigated in this paper.

Objectives: The aim of this paper is to investigate the effectiveness of couples therapy with a narrative therapy approach for reducing couples' conflicts.

Methods: This semi-experimental study used pre-test and post-test assessments to examine the efficiency of the narrative therapy approach. The study population consisted of all couples who had been married for at least 5 years and were referred to a psychology clinic for marital conflicts. Thirty couples (60 participants) were selected randomly and then split into two groups of 15 couples each an experimental group and a control group. A pre-test inventory of marital conflict via a validated form was completed for both groups. Next, 8 sessions of group counseling (couples therapy with a narrative therapy approach) was performed for the experimental group while the control group remained untreated. Finally, a post-test inventory of marital conflict was completed for both groups.

Results: The analysis of covariance of the couples' marital conflicts between the experimental and control groups was significant $(\mathrm{P} \leq 0.001$, F value $=104.8$, confidence level: $99 \%)$. The intervention of therapy reduced couples' conflicts, increased the level of their cooperation, and improved their sexual relationship.
\end{abstract}

Conclusions: The results of this study show that narrative therapy is a suitable approach for solving couples' conflicts.

Keywords: Couples Therapy, Group Therapy, Marital Conflicts, Narrative Therapy

\section{Background}

The family is one of the most basic and important social units and has a deep impact on the physical and mental health of individuals. It can also influence the health of the community (1). The family is required to establish and maintain close relationships with others and is considered a basic human motivation. Many people believe that marriage is one of the most intimate adult relationships and a main source of affection and support (2). Marital adjustment, which has long been of interest to psychologists and sociologists, is one of the most widespread implications for determining the happiness level and sustainability of the relationship (3). Conflict among couples is one of the most important issues in the family (2). It is also a common reason for which wives will refer for treatment (4). Marital conflict is known by systemic therapists as a conflict over the ownership of the positions of authority and the disregard for each other's significance. Marital conflict is a result of a couple's differences regarding demands, selffulfillment needs and their methods of satisfaction, behavioral stereotypes, and irresponsible behavior towards the marital relationship and marriage in general (5).

Potential disorders of conflict include emotional, cognitive, and physiological disorders. Suspicion, anxiety, irritability, anger, depression, and guilt are all emotional disorders of conflict (6). Conflict can cause cognitive impairment. Situations of conflict also often disturb a person's thinking patterns, quality of decision-making, and cognition (7-10).

Since the family's performance is one of the most important aspects of a person's life, several studies have been conducted to determine the effectiveness of various approaches for improving said performance. One of the most important approaches used for this aim is narrative therapy (11). Narrative therapy was born in the 70s and 80s. The literal meaning of the word "narrative" is "story" and nar- 
rative therapy speaks about the importance of people's stories of their lives. According to the narrative theory, people tend to consider their life a consistent and logically important story so that they can advance their goals and expectations for the future. The process of constructing this story is a natural one that helps people to understand themselves and their experiences $(12,13)$.

Narrative therapists help enable clients to change negative beliefs, values, and interpretations without imposing their own value systems and interpretations. These therapists want to create new meanings and possibilities from their clients' narratives (14).

One feature of narrative-focused couple therapy is an "optimism" about the nature of the problems. People can re-create their lives actively and continually and narrative therapists want clients to create different narratives through "unique outcomes". The turning point in the narrative interviews may come at the time when clients decide to continue living according to their story that is full of difficulty or when they create another story. At this point, the therapist helps clients to build more coherent and comprehensive narratives. The appearance of another story is a sign of hope (15).

Ghaderi et al. (16) studied the effects of narrative therapy on emotional control in teenage girls. The results showed that narrative therapy had an important effect on controlling negative emotions such as anger and promoting positive emotions in teenagers.

Researchers have mainly focused on the effectiveness of narrative therapy on psychiatric disorders rather than on couples' conflicts. For example, Naziri et al. (17) studied the effectiveness of the narrative therapy approach for reducing depression in women. Their results showed that the level of depressive symptoms, negative automatic thoughts, and inoperative attitudes in the experimental group were less than the control group (18). Bassak Nazhad et al. (19) studied the effectiveness of group narrative therapy for concerns about the malformed body image in female students. Findings showed that narrative therapy reduced said concerns in the experimental group in contrast to the control group after an interval of two months. Thus, the researchers showed the usefulness of narrative therapy over the time. In another study, Sotoudeh Navroudi et al. (20) evaluated the effectiveness of reminiscence therapy in a group for the mental health of older men. Findings showed that group reminiscence leads to improved mental health components (somatic symptoms, anxiety, insufficient social activity, and depression) in older men (21).

\section{Objectives}

The aim of the current study was to investigate the efficacy of couple therapy with a narrative approach in reducing couples' conflicts.

\section{Methods}

This semi-experimental study used pre-test and posttest assessments of both study groups to test the results of narrative therapy on reducing couples' conflicts.

\subsection{Study Population and Subjects}

The study population included all couples who had been married for at least 5 years and referred to a psychology clinic for marital conflicts. Thirty-five couples were selected randomly for participation in this study. Seventeen couples were randomly allocated to the experimental group and 18 couples were randomly allocated to the control group. The following steps were then applied in sequence.

The first step was a pre-test inventory of marital conflicts performed for both groups.

The second step was eight sessions of group counseling (marital therapy with a narrative therapy approach) performed for the couples in the experimental group. In the control group, pre-test and post-test assessments were performed without an intervention.

The first session of group counseling involved the introduction of members, the explanation of the rules, and the creation of a therapeutic space. The second session involved the expression of life stories. The third session involved the investigation of the situations that made the couples sad, the expression of conflicting thoughts, and the expression of goals which had not been achieved. The fourth session involved an audience of external witnesses and group members listening to the story of references and expressing their viewpoints. The audience also cited similar experiences and offered feedback to the clients.

The fifth session involved the intellectual foundation through changing the view that an individual is not the problem, then separating the problem from the person and giving him or her a chance to observe the issue from an outside perspective. The sixth session involved naming the problem, which allowed the individual to comfortably be separate from the issue and be aware of how it influenced his or her life. This also promoted a feeling of control in the person and reduced the feelings of shame and guilt. The seventh session involved describing unique outcomes. The purpose of this was to identify the cases in which the person stood successfully against difficulties. The eighth session involved creating with the help of the therapist an 
alternative and more positive story including the unique outcomes in order to give a new meaning to one's life.

The third step was a post-test inventory of marital conflicts performed for the control and experimental groups.

\subsection{Assessment Instrument}

The assessment instrument used in this study is a revised inventory of marital conflicts containing 54 items. This inventory is used for evaluating couples' conflicts and considers 8 dimensions: decrease of cooperation, decrease of sexual relationship, increase of emotional reaction, increase of gaining the child(ren)'s support, increase of personal relationship with their own family, decrease of familial relationship with their partner's family and friends, separation of finances, and decrease of effective communication. The internal consistency (Cronbach's alpha coefficient) for the entire inventory tested on a group of 270 individuals is equal to 0.96 , proving the inventory's validity. In the step of content validity, after preliminary implementation and measure the correlation of each question with total inventory and their scales, any item did not remove because of good correlation for all questions (22).

All ethical issues were considered before each subject's enrollment. All subjects were free to participate in this study and their information was kept confidential.

\section{Results}

Two couples in the experimental group and 3 couples in the control group dropped out of the study. A total of 15 couples completed the study in the experimental group and 15 couples completed the study in the control group. Descriptive and analytical statistical methods were used for data analysis in this study. The normality of the data distribution was checked with the Kolmogorov-Smirnov test. An analysis of covariance was used to test the hypothesis.

As seen in Table 1, the average scores of marital conflicts, the decrease in couples' cooperation, and the decrease of sexual relationships in the experimental and control groups are close to each other in the pre-test assessment.

As seen in Table 2, the post-test assessment showed a considerable difference between the average scores of marital conflicts, the decrease of cooperation, and the decrease of sexual relationship in the experimental and control groups.

Table 3 shows that the analysis of covariance of the couples' marital conflicts in the experimental and control groups was significant $(\mathrm{P} \leq 0.001, \mathrm{~F}$ value $=104.8)$. Therefore, it can be concluded that the implementation of group counseling with the approach of narrative therapy is effective in reducing marital conflicts (confidence level: 0.99\%).
As can be seen in Table 4, the analysis of covariance of the couples' cooperation levels in the experimental and control groups was significant $(\mathrm{P} \leq 0.001$, F value $=121.66)$. Therefore, it can be concluded that the implementation of group counseling with the approach of narrative therapy is effective in increasing couples' cooperation levels (confidence level: $0.99 \%$ ).

Table 5 shows the analysis of covariance of couples' sexual relationships in the experimental and control groups. The difference was found to be significant $(\mathrm{P} \leq 0.001, \mathrm{~F}$ value $=81.97)$. Therefore, it can be concluded that the implementation of group counseling with the approach of narrative therapy is effective in improving couples' sexual relationships (confidence level: 0.99\%).

\section{Discussion}

The aim of this study was to determine whether couples therapy with the narrative therapy approach is effective in reducing couples' conflicts.

The results of the analysis of covariance indicated that the F-value calculated for the differences of the two groups' post-test scores compared to their pre-test scores is equal to 104.8, which is significant $(\mathrm{P} \leq 0.001$,). Therefore, it can be concluded that the implementation of group counseling with the approach of narrative therapy is effective for reducing marital conflicts (confidence level: $99 \%$ ).

The results of the analysis of covariance indicated that the F value calculated for the differences of the two groups' post-test scores compared to their pre-test scores is equal to 121.66, which is significant $(\mathrm{P} \leq 0.001)$. Therefore, it can be concluded that the implementation of group counseling with the approach of narrative therapy is effective for increasing couples' cooperation levels (confidence level: 99\%).

The results of the analysis of covariance indicated that the F value calculated for the differences of the two groups' post-test scores compared to their pre-test scores is equal to 81.97, which is significant $(\mathrm{P} \leq 0.001)$. Therefore, it can be concluded that the implementation of group counseling with the approach of narrative therapy is effective for increasing couples' sexual relationships (confidence level: $99 \%)$.

The results obtained from this study agree with those of many other previous studies. For example, Boustan (23) performed a comparative investigation of the effectiveness of group couples therapy with the "treatment of re-deciding" and "narrative therapy" approaches on increasing marital satisfaction in married students. This research showed that narrative therapy and the treatment of re-deciding was effective in increasing marital satisfaction. Rabiee et al. (24) performed an investigation of the 
Table 1. Descriptive Indexes Related to Pre-Test Scores in the Experimental and Control Groups

\begin{tabular}{|c|c|c|c|c|c|c|c|}
\hline Variable & Group & $\begin{array}{l}\text { Number of } \\
\text { Participants }\end{array}$ & Average & Minimum Value & Maximum Value & $\begin{array}{l}\text { Standard } \\
\text { Deviation }\end{array}$ & $\begin{array}{c}\text { Standard Error of } \\
\text { Mean }\end{array}$ \\
\hline \multirow{2}{*}{ Marital conflicts } & experimental & 30 & 140.77 & 98 & 185 & 22.51 & 4.20 \\
\hline & control & 30 & 152.23 & 102 & 179 & 20.65 & 3.77 \\
\hline \multirow{2}{*}{$\begin{array}{l}\text { Decrease of } \\
\text { cooperation }\end{array}$} & experimental & 30 & 13.93 & 6 & 22 & 4.43 & 0.80 \\
\hline & control & 30 & 15.66 & 7 & 19 & 3 & 0.54 \\
\hline \multirow{2}{*}{$\begin{array}{l}\text { Decrease of } \\
\text { sexual } \\
\text { relationship }\end{array}$} & experimental & 30 & 14.03 & 8 & 22 & 3.17 & 0.58 \\
\hline & control & 30 & 15.36 & 8 & 22 & 3.87 & 0.70 \\
\hline
\end{tabular}

Table 2. Descriptive indexes Related to Post-Test Scores in the Experimental and Control Groups

\begin{tabular}{|c|c|c|c|c|c|c|c|}
\hline Variable & Group & $\begin{array}{c}\text { Number of } \\
\text { Participants }\end{array}$ & Average & Minimum Value & Maximum Value & $\begin{array}{l}\text { Standard } \\
\text { Deviation }\end{array}$ & $\begin{array}{c}\text { Standard Error of } \\
\text { Mean }\end{array}$ \\
\hline \multirow{2}{*}{ Marital conflicts } & experimental & 30 & 109.4 & 86 & 146 & 15.80 & 2.88 \\
\hline & control & 28 & 152.40 & 104 & 177 & 19.50 & 3.56 \\
\hline \multirow{2}{*}{$\begin{array}{l}\text { Decrease of } \\
\text { cooperation }\end{array}$} & experimental & 30 & 9.13 & 5 & 14 & 2.50 & 0.45 \\
\hline & control & 28 & 16.2 & 10 & 22 & 3.15 & 0.58 \\
\hline \multirow{2}{*}{$\begin{array}{l}\text { Decrease of } \\
\text { sexual } \\
\text { relationship }\end{array}$} & experimental & 30 & 9.40 & 6 & 15 & 2.41 & 0.44 \\
\hline & control & 28 & 15.46 & 8 & 22 & 3.74 & 0.68 \\
\hline
\end{tabular}

Table 3. Results of the Analysis of Covariance of Couples' Marital Conflicts in the Experimental and Control Groups

\begin{tabular}{|c|c|c|c|c|c|}
\hline Source Of Variations & Sum of Squares & Degree of Freedom & Mean Square & FValue & P Value \\
\hline Pre-test conflicts & 7977.86 & 1 & 7977.86 & 44.22 & $\leq 0.001$ \\
\hline Group & 18906.23 & 1 & 18906.23 & 104.8 & $\leq 0.001$ \\
\hline
\end{tabular}

Table 4. Results of the Analysis of Covariance of Couples' Cooperation Levels in the Experimental and Control Groups

\begin{tabular}{|c|c|c|c|c|c|}
\hline Sources of Variation & Sum of Squares & Degree of Freedom & Mean Square & F Value & P Value \\
\hline Pre-test conflicts & 215.19 & 1 & 215.19 & 48.08 & $\leq 0.001$ \\
\hline Group & 544.42 & 1 & 544.42 & 121.66 & $\leq 0.001$ \\
\hline
\end{tabular}

Table 5. Results of the Analysis of Covariance of Couples' Sexual Relationships in the Experimental and Control Groups

\begin{tabular}{|c|c|c|c|c|c|}
\hline Sources of Variation & Sum of Squares & Degree of Freedom & Mean Square & F Value & P Value \\
\hline Pre-test conflicts & 304.06 & 1 & 304.06 & 63.58 & $\leq 0.001$ \\
\hline Group & 392 & 1 & 392 & 81.97 & $\leq 0.001$ \\
\hline
\end{tabular}

effectiveness of couples' narrative therapy in improving the family functioning of couples. The results obtained from this study showed that couples' narrative therapy improves family functioning, and has been effective for other aspects of family functioning except religious emphasis and interrelatedness. The effect of this approach on fam- ily functioning and its dimensions did not differ between genders. Also, there were no differences between men and women in family practices. The results of Adamz's study, quoted by Chahar Mahali (25), and the results of Intayer's study, quoted by Rabiee et al. (24), are also consistent with the findings of this study. 
The effect of narrative therapy on the tendency to forgive in women was evaluated by Nouri Tirtashi et al. (26), who found that this tendency increased in the experimental group in comparison with the control group. Makkiyan et al. (27) compared the efficacy of narrative therapy and diet therapy on the Body Mass Index in overweight and obese women. Their findings showed that diet therapy by itself did not have a significant effect on reducing the Body Mass Index, but when narrative therapy and diet therapy were both used in a group, a significant reduction was observed. These studies suggest that narrative therapy, in addition to having the positive effect of reducing conflicts between couples, is effective for treating other health problems. Studies conducted by Hamidi Pour et al. (28), Mirahmadi et al. (29), Alavi Zadeh et al. (30), Batlani et al. (31), and Roshan et al. (32) suggest that other approaches of couples therapy, such as a narrative therapy approach, can reduce conflicts between couples and increase marital satisfaction. Bray et al. (33) examined the effectiveness and prolonged effect of couple therapy in the prevention of separation and divorce. Their results suggest that couples therapy is effective in reducing marital conflicts and increasing marital satisfaction.

\subsection{Conclusion}

According to the findings obtained from this study and other similar studies, it can be concluded that narrative therapy is a suitable approach for solving couples' conflicts. This treatment may have a positive effect on the life performance of married couples. It is recommended that specialists in the field of marital therapy consider this treatment when working with clients.

\section{Acknowledgments}

The authors would like to thank the psychiatry research center of Roozbeh hospital, Tehran University of Medical Sciences, as well as all of the couples who participated in this research for their cooperation and support.

\section{Footnote}

Authors' Contribution: Parvin Hamidi and Seyfollah Bahari designed and performed the study protocol. Morteza Shamohammadi and Seyed-Ali Mostafavi prepared and wrote the manuscript. All of the authors have read and approved the manuscript.

\section{References}

1. Chin-Quee D, Mugeni C, Nkunda D, Uwizeye MR, Stockton LL, Wesson J. Balancing workload, motivation and job satisfaction in Rwanda: assessing the effect of adding family planning service provision to community health worker duties. Reprod Health. 2016;13:2. doi: 10.1186/s12978-015-0110-z. [PubMed: 26732671].

2. Schooreel T, Verbruggen M. Use of family-friendly work arrangements and work-family conflict: Crossover effects in dual-earner couples. J Occup Health Psychol. 2016;21(1):119-32. doi: 10.1037/a0039669. [PubMed: 26322442].

3. Pratt KJ, Palmer E, Cravens JD, Ferriby M, Balk E, Cai Y. Marriage and Family Therapy Trainees' Reports of Explicit Weight Bias.J Marital Fam Ther. 2016;42(2):288-98. doi: 10.1111/jmft.12116. [PubMed: 25728034].

4. Tachi T. Couple therapy with parents whose youngest daughter had a psychotic episode: impairment of a child and marital conflict. Tokai J Exp Clin Med. 1991;16(2):103-9. [PubMed: 1780911].

5. Dillon LM, Nowak N, Weisfeld GE, Weisfeld CC, Shattuck KS, Imamoglu OE, et al. Sources of marital conflict in five cultures. Evol Psychol. 2015;13(1):1-15. [PubMed: 25560390].

6. Ahmadi SM, Mohammadi MR, Mostafavi SA, Keshavarzi S, Kooshesh $\mathrm{SM}$, Joulaei H, et al. Dependence of the geriatric depression on nutritional status and anthropometric indices in elderly population. Iran J Psychiatry. 2013;8(2):92-6. [PubMed: 24130608].

7. Mercado E, Hibel LC. The impact of marital conflict on maternal regulation of infant cortisol and emotional functioning. Psychoneuroendocrinology. 2015;61:21-2. doi: 10.1016/j.psyneuen.2015.07.448. [PubMed: 26383334].

8. Tu KM, Erath SA, El-Sheikh M. Coping responses moderate prospective associations between marital conflict and youth adjustment. $J$ Fam Psychol. 2016;30(5):523-32. doi: 10.1037/fam0000169. [PubMed: 26571195].

9. Rezaeian M.H. R., Mostafavi SA, athinejad A, Ranjbar E, Bidaki R. Prevalence of sleep disorders in medical internship students of Rafsanjan University of Medical Sciences. Int J Clin Surg Advance. 2014;2(4):74-81.

10. Hasheminasab Zaware R, Mahmoodi Meymand MH, Rezaeian M, Mohammadi Kamalabadi N, Mostafavi SA, Abdolkarimi Dawarani MA, et al. Insomnia and Restless Leg Syndrome in Patients Undergoing Chronic Hemodialysis in Rafsanjan Ali Ibn Abitaleb Hospital. Nephrourol Mon. 2016;8(1):29527. doi: 10.5812/numonthly.29527. [PubMed: 26981494].

11. Williams-Reade J, Freitas C, Lawson L. Narrative-informed medical family therapy: using narrative therapy practices in brief medical encounters. Fam Syst Health. 2014;32(4):416-25. doi: 10.1037/fsh0000082. [PubMed: 25329755].

12. Gwozdziewycz N, Mehl-Madrona L. Meta-analysis of the use of narrative exposure therapy for the effects of trauma among refugee populations. Perm J. 2013;17(1):70-6. doi: 10.7812/TPP/12-058. [PubMed: 23596375].

13. Cashin A, Browne G, Bradbury J, Mulder A. The effectiveness of narrative therapy with young people with autism. J Child Adolesc Psychiatr Nurs. 2013;26(1):32-41. doi: 10.1111/jcap.12020. [PubMed: 23351106].

14. Looyeh MY, Kamali K, Shafieian R. An exploratory study of the effectiveness of group narrative therapy on the school behavior of girls with attention-deficit/hyperactivity symptoms. Arch Psychiatr Nurs. 2012;26(5):404-10. doi: 10.1016/j.apnu.2012.01.001. [PubMed: 22999036].

15. Leahy MM, O’Dwyer M, Ryan F. Witnessing stories: Definitional Ceremonies in Narrative Therapy with adults who stutter. $J$ Fluency Disord. 2012;37(4):234-41. doi: 10.1016/j.jfludis.2012.03.001. [PubMed: 23218207].

16. Ghaderi Z, Khodadadi Z, Abbasi Z. Influence of combinationgroup therapy in style of re- decision- making and narrative therapy to controlthe emotions of teen girls in Shiraz. J Woman Society. 2011(3):13748.

17. Naziri G, Ghaderi Z, Zare F. The effectiveness of the narrative therapy approach for reducing depression inwomen, in Marvdasht. J Woman Society. 2010;1(2):65-78. 
18. Asadpour M. R. B. , Rajabi Z, Mostafavi SA, Khaje-Karimaddini Z. Attitude toward death in nursing staffs in hospitals of Rafsanjan (South East Iran). Nur Practice Today. 2015;2(2):43-51.

19. Bassak Nazhad S, Mehrabi Zadeh Honarmand M, Hasani M, Nargesi F. Investigation efficacy of group narrative therapy on concerns about malformedbody in female students. Sci-Res Quarter J Health Psychol. 2013;2:5-11.

20. Sotoudeh Navroudi SA, Pour Agha Roudbordeh F, Kafi SM, PourNesaiee G. A. . Influence of reminiscence group practices on mental health in elderly men.J Guilan Uni Med Sci. 2012;22(85):61-7.

21. Ahmadi SM, Keshavarzi S, Mostafavi SA, Bagheri Lankarani K. Depression and Obesity/Overweight Association in Elderly Women: a Community-Based Case-Control Study. Acta Med Iran. 2015;53(11):6869. [PubMed: 26786989].

22. Thanaiee Zaker B, Alaghband S, Houman A. Measures of family and marriage. Tehran, Iran: Besat publication; 2001.

23. Boustan A. A comparative study of group couple therapy by learning (re-decidingtreatment) and (narrative therapy) approaches on increasing the maritalsatisfaction in married students. Tehran, Iran: Islamic Azad University, Science and Research Branch; 2009.

24. Rabiee S, Fatehi Zadeh M, Bahrami F. Investigation efficacy of couple's narrative therapy on couple familyfunctioning in Isfahan city.J Family Studies. 2010;4(14):179-91.

25. Chahar mahali F. Narrative review of compatible and incompatible married women. Tehran, Iran: University of Welfare and Rehabilita- tion Sciences; 2006.

26. Nouri Tirtashi E, Kazemi N. Investigation efficacy of narrative therapy on the tendency to forgiveness inwomen.J Clin Psychol. 2012;4(2):71-8.

27. Makkiyan SA, Skandari H, Borjali A, Ghodsi D. Comparative efficacy of narrative therapy and diet therapy on body massindex in overweight and obese women. Iranian J Nutr Sci Food Technol. 2010;5(4):53-63.

28. Hamidi Pour R, Thanaiee Zaker B, Nazari AM, Farahani MN. Investigation efficacy of group couple therapy on the base of forgivingness onmarital satisfaction. Women's Social -Psychological Studies. 2011;8(4):49-72.

29. Mirahmadi SL, Ahmadi SA, Bahrami F. Effectiveness of short- term couple therapy as a way of regulating thehappiness and mental health of couples in Isfahan. New Findings Psychol. 2011;7(22):33-43.

30. Alavi Zadeh SMR. Couples therapy based on short- term selfregulation: Helping couples to helpthemselves. Thought Manner. 2011;4(16):27-36.

31. Batlani S, Ahmadi S. A. , Bahrami F, Shah Siyah M, Mohebbi S. Couple therapy effect on the base of sexual satisfaction and intimacy.J Mental Health Doctrine. 2011;12(2):496-505.

32. Roshan R, Alinaghi AR, Tavali A. Investigation efficacy of couple therapy based on self- regulation on reducingmarital conflict. J Clin Psychol. 2010;1(1):1-14.

33. Bray JH, Ernest JN. Treatment of marital conflict and prevention of divorce. J Marital Family Therapy. 1995;4:461-73. 